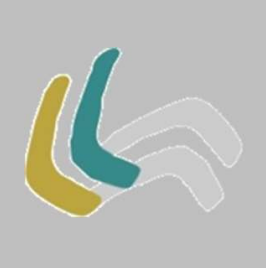

\title{
A IMENSIDÃO DOS INTERIORES: O MERGULHO INTROSPECTIVO NOS POEMAS DE MARTA CHAVES
}

\author{
THE IMMENSITY OF INTERIORS: \\ THE INTROSPECTIVE DIVE PRESENT \\ IN THE POETRY OF MARTA CHAVES
}

\author{
Júlia Nunes Azzi ${ }^{1}$ \\ Universidade Federal do Rio Grande do Sul
}

\begin{abstract}
Resumo: Este trabalho propõe um estudo sobre a poética de Marta Chaves, centrando-se no movimento de introspecção e reflexão que seus poemas apresentam e analisando-os como uma forma de procurar sentidos na interioridade do $e u$, em meio à solidão. Este estudo concentra-se em três poemas do livro Varanda de inverno (2018): "Solar", "Banquete" e "Primeiro: continuar. Segundo: começar". Objetiva-se compreender de que maneira é construída essa atmosfera íntima, através de uma análise das escolhas vocabulares e sonoras e das imagens criadas nos poemas, e, a partir disso, refletir sobre como essa introspecção carrega consigo a ideia de um descortinar do mundo, a partir da investigação do ser. Como aporte teórico, são utilizadas as ideias de teóricos como Gaston Bachelard (1978), Victor Chklovski (1971) e Iuri Tynianov (1975), dentre outros.
\end{abstract}

Palavras-Chave: Marta Chaves; Varanda de inverno; Introspecção; Intimismo; Reflexão sobre o eu.

1 Endereço eletrônico: julianazzi@hotmail.com. 
Abstract: This assignment proposes a study of Marta Chaves's poetry, focusing on the introspective and reflective movement that is present in her poems and interpreting these movements as a way to search for meaning within the self, amongst solitude. This study focuses on three poems from the book Varanda de inverno (2018): "Solar", "Banquete" and "Primeiro: continuar. Segundo: começar". The objective is to comprehend the manner in which this intimate atmosphere - noticeable both in these poems and in the collection as a whole - seems to unravel the world starting from the investigation of the self. As a theoretical basis, this paper will approach ideas from authors such as Gaston Bachelard (1978), Victor Chklovski (1971) and Iuri Tynianov (1975), among others.

Keywords: Marta Chaves; Varanda de inverno; Introspection; Intimacy; Reflection on the self.

\section{INTRODUÇÃO}

Varanda de inverno, publicado em 2018, é o mais recente livro da poeta portuguesa Marta Chaves. Em poemas concisos, mas carregados de sentidos em sua intensidade silenciosa, percebe-se as marcas de uma primeira pessoa reflexiva, que, a partir de uma postura introspectiva, voltada para o interior, parece investigar o entorno, a palavra, a vida e a si mesma, procurando por sentidos que permanecem sempre semoventes.

Nascida em Coimbra em 1978, Marta Chaves atua como psicóloga e psicoterapeuta, além de poeta, e publicou seu primeiro livro, Onde não estou, tu não existes, em 2009. Desde então, passou a publicar com frequência quase anual, porém, após Perda de inventário (2015), houve três anos de silêncio até o nascimento de Varanda de inverno, que é o seu sexto livro. O título realça a atmosfera íntima dos poemas, que são marcados por uma tristeza calma, maturada, sentimento que se enovela nas reflexões dispostas pelos poemas, mesmo naqueles poucos em que o eu não está manifesto.

Pensemos em um sujeito poético que, no inverno, olha para o entorno, a partir de sua varanda, e pondera. Pode-se enxergar, à luz dos poemas, a imagem da varanda como uma transição entre dois mundos: a casa, mundo íntimo e protegido, e a rua, aquilo que se externa. É uma abertura, mas não completa. No isolamento, um olhar que faz sua trajetória de dentro para fora, como nos poemas. A contemplação permanece no espaço da interioridade, mais perto da 
casa do que da rua, mas, ainda assim, não completamente em casa a ponto de se encarar apenas paredes. “Esfreguei os olhos / na esperança de que o mundo / surgisse diferente" (CHAVES, 2018, p. 56), diz o poema "Idade de ouro", no qual o mundo aparece em um segundo plano após a presença que o enxerga: esfregase os olhos, como se a atividade corporal pudesse reverberar externamente.

Esses versos representam uma tendência geral: um olhar que vai do mais interno ao mais externo, porém sem a ilusão de mudar a realidade do mundo pela fantasia, como demonstra o poema "Alfândega": "Agora aceito a inevitabilidade / das leis que me proscrevem" (CHAVES, 2018, p. 13). A rua torna-se estreita e a realidade revela suas limitações. Porém, ainda há o movimento introspectivo que se volta para a própria interioridade como forma de compreender, ou, ao menos, questionar, o mundo. Esse movimento é uma interrupção da vida de pressas e choques, e, nesse ponto, já é uma espécie de resistência. O sujeito refugia-se na própria solidão como uma forma de compreender as próprias experiências, ou melhor, como uma forma de, de fato, ter uma experiência.

Jorge Larrosa Bondía (2002), reflete sobre essa noção de ter uma experiência, partindo das ideias expressas por Walter Benjamin, mas as direcionando para uma reflexão sobre o que significa experienciar em um sentido mais individual e sobre que tipo de atitude está implicada em um "saber da experiência". Segundo o autor, para se ter uma experiência, vivenciar algo que nos afete de verdade, é preciso um gesto de interrupção, "um gesto que é quase impossível nos tempos que correm: requer parar para pensar, parar para olhar, parar para escutar, pensar mais devagar [...] suspender o automatismo da ação, cultivar a atenção e a delicadeza [...] calar muito, ter paciência e dar-se tempo e espaço" (BONDÍA, 2002, p. 24), até porque a experiência está muito ligada ao modo como cada indivíduo a acomoda e se deixa transformar de alguma maneira, já que não se trata daquilo que acontece de uma maneira impessoal, mas 
do que acontece a cada ser, subjetivamente. Nesse sentido, está ligada a um movimento de introspecção.

A atmosfera de introspecção, no livro de Marta Chaves, já é sugerida pela ideia de inverno no título, que sugere recolhimento, considerando que, a partir do Solstício de inverno, as noites se tornam mais longas que o dia, aumentando a escuridão circundante e a busca por abrigo. $\mathrm{O}$ isolamento está expresso em poemas como "Olimpo": "e aqui onde estou / o vento sopra a tua ausência" (CHAVES, 2018, p. 29), que, principalmente pela expressão "aqui onde estou", sugere uma distância, complementada pelo título. $\mathrm{O}$ frio leva a uma diminuição do ritmo e à reclusão no interior, envolvendo-se em silêncio. A linguagem contida de Marta Chaves possui também algo de invernal em seu caráter sóbrio - imagens de melancolia parecem rondar sua poética, a partir do discreto ar gélido e, consequentemente, do recolhimento que se apresenta, trazendo a característica de lentidão e de voltar-se a si, que é comumente associado ao temperamento melancólico. Porém, ao mesmo tempo, há uma intensidade subterrânea - o sol na varanda, talvez. Por isso, essa poética poderia ser pensada como a "melancolia sem tragédia", que Eduardo Lourenço $(1999$, p. 31) associa à sensibilidade portuguesa. De acordo com o autor, essa sensibilidade específica chega marcada muito mais pela saudade do que pela ideia clássica da melancolia, como um luto sem objeto, uma falta que leva ao desespero. Há uma leveza, pouco trágica, misturada à tristeza de quem contempla.

Sua poética é uma poética de fim de dia, na qual a linguagem é tecida como uma maneira de se desfazer a trança, como expresso no mesmo poema: “o dia finda quando me desembaraço / desta trança enorme" (CHAVES, 2018, p. 29). Sobre o peso dessa trança (o peso de um dia inteiro no corpo) sobrepõe-se a leveza do ato de desembaraçar. Porém, nesse ato, há uma procura. Essa espécie de procura íntima, de investigação da existência e geração de sentidos a partir do silêncio percorre os poemas. A própria concisão em suas construções é uma 
espécie de silêncio de tudo que não está colocado, gerando uma tensão de sentidos e obrigando o leitor a reconstruí-lo em si. "Treino disciplinadamente o silêncio" (CHAVES, 2018, p. 27), diz no poema "Não te esqueças de viver", representando o espaço de escuta em que se coloca, já que é necessário calar-se para ouvir a si mesma e ao mundo, para dar vazão à procura.

Essa procura se relaciona com a vontade de encontrar-se naquilo que é observado e refletido, atitude para a qual se faz necessária a solidão. Vários poemas representam momentos de reflexões, como uma ponderação que gira em torno de si mesma, sem fornecer respostas: “Quero saber como seria / Se não tivéssemos olhos nem boca. / O que nos seria dado a ver e dizer / através do espírito" (CHAVES, 2018, p. 12). A escuta também é importante, uma escuta sintonizada com o mundo, que está atenta para apreender o instante: "Sopro as cinzas e escuto o presente" (CHAVES, 2018, p. 55). O presente está no horizonte dessa procura, sendo que muitos poemas parecem capturas de pensamentos e reflexões ligeiros.

Essa busca pode ser vista como uma tentativa de desautomatizar as percepções nubladas pelo cotidiano, o que é, para Victor Chklovski (1971, p. 45), o objetivo da arte: "E eis que para devolver a sensação de vida, para sentir os objetos, para provar que pedra é pedra, existe o que se chama arte. O objetivo da arte é dar a sensação do objeto como visão e não como reconhecimento". Esse movimento de desautomatização pode ser visto no nível do conteúdo, com esse eu-lírico que tenta ter a visão dos objetos - seja o entorno, o presente, a linguagem, o silêncio, as emoções ou a si mesmo - e não apenas o reconhecimento que é automático e inconsciente, e que é a forma econômica com que nos dirigimos ao mundo, na maior parte das vezes. Porém, isso não aparece apenas na temática, mas está presente enquanto procedimento nos poemas. As reflexões dirigem o leitor a novas percepções, e a própria concisão gera 
estranhamento a partir da tensão dos sentidos possíveis, considerando que, segundo Chklovski, esse efeito é gerado a partir de um obscurecimento da forma.

Como um modo de compreender a manifestação da busca introspectiva a partir do silêncio e da solitude, que se estabelece ao longo do livro, serão analisados três poemas que revelam facetas diferentes dessa questão. Essa análise explora aspectos rítmicos, imagéticos e temáticos, que se combinam e se imbricam na textura de cada poema. Visto que, de acordo com Iuri Tynianov (1975a), o ritmo é o fator construtivo do verso, agindo como subordinante em relação aos outros elementos, muitas das reflexões partem da sonoridade dos versos para analisar os sentidos que estão sendo criados, simultaneamente, pelos diversos recursos de construção dos poemas. As imagens presentes nos textos são analisadas a partir de seus significados no imaginário coletivo, pensando de que forma constroem em suas fímbrias a ideia de uma procura nos confins do indivíduo. Para a análise desses elementos, recorre-se a ideias de Gaston Bachelard (1978) e a conceitos do Dicionário de Símbolos, de Jean Chevalier e Jean Gheerbrant (2001), em conjunto com reflexões sobre experiência, introspecção, melancolia e solidão.

\section{$1 \quad$ VIDA INTERNA SOB O SOL}

O primeiro poema a ser analisado chama-se "Solar"

1. Poderia praticar esta forma de vida

2. que me assenta melhor do que a minha.

3. Quero dizer

4. é dentro da cabeça

5. e fora da minha vida

6. que me sinto menos só.

7. Poderia ficar aqui algum tempo

8. deslocando a cadeira

9. para acompanhar a trajectória do sol. 
10.Não o faço.

11.Abro a porta que dá para a casa

12.e deixo devoluta a vida

13.imaginária no jardim. (CHAVES, 2018, p. 16)

Este poema é construído em torno de uma dualidade: há duas formas de vida, que se colocam de lados opostos. Uma delas é a que o eu-lírico considera como dele, enquanto a outra é a que mais the apraz: a vida de "dentro da cabeça". Porém, é nessa última que os indicadores do momento presente recaem. Todas as referências espaciais de onde o eu-lírico se encontra são no espaço dessa outra vida, ela é a que ocupa o centro do poema, a que se quer descrita, como mostram dêiticos como: "esta" no verso 1, e "aqui", no verso 7. Da outra, a vida "minha", ou seja, a vida do eu-lírico, só sabemos uma porta e uma solidão. Pode-se lê-la como a vida prática, dos acontecimentos, do trabalho, em oposição à vida em que se considera menos sozinho, que é a vida interior, evocada no quarto verso.

A palavra "vida" aparece três vezes no poema, sempre em evidência, devido à sua posição no final de versos, mas, além disso, é possível contar como uma quarta aparição no verso 2, quando é sugerida de maneira elíptica (e a partir da sonoridade) na palavra "minha". No entanto, essas vidas, que, enquanto palavras, rimam entre si, no plano do significado se opõem umas às outras. As ocorrências no verso 1 e no verso 12 se referem à vida interior, aquela que acontece no jardim (que, no último verso, retoma "vida" a partir de sua sonoridade similar). Essa vida "assenta-lhe melhor", ou seja, é a que se ajusta mais consigo, talvez porque mais importante do que a outra, que é a vida imperativa, aquela chamada de "minha". As ocorrências no verso 2 (por elipse) e no verso 5 referem-se a essa vida, sobre a qual pouco sabemos, e que é externa ao mergulho na mente. Nas duas menções, ela é referida a partir de negativas, ajustando-se menos que a outra.

Desde o início do poema, somos apresentados ao reino das possibilidades. Ambas as estrofes iniciam com o verbo "poderia" e nos dois casos o verbo aponta 
para a vida interna: ela é uma possibilidade, mas não de início e sim de continuação, já que - como sugerem os pronomes - o eu-lírico já está vivenciando esse momento. Aquilo a que a primeira estrofe alude de forma mais abstrata, a segunda estrofe traz concretamente, correspondência que se dá também de forma sonora, na forma como, por exemplo, "cadeira" retoma "cabeça" e "sol" retoma "só". Ambas as descrições estão intrincadas. A vida de mover a cadeira no jardim acompanhando o sol é a vida de dentro da cabeça, da interioridade, e de se sentir menos só.

Essa vida interna - riquíssima até mesmo pela classificação enquanto "vida" e por fornecer dentro de si a própria companhia - pode ser relacionada às ideias de Bachelard (1978, p. 317) sobre a imensidão. Segundo o autor, "a imensidão está em nós. Está presa a uma espécie de expansão do ser que a vida refreia, que a prudência detém, mas que volta de novo na solidão. Quando estamos imóveis, estamos além; sonhamos num mundo imenso. A imensidão é o movimento do homem imóvel". Esse movimento de devaneio leva a uma consonância entre o espaço da intimidade e o espaço do mundo. É isso que muitos dos poemas parecem sugerir, e que o espaço da varanda de inverno insinua: esse encontro com o mundo, que ocorre a partir de um primevo encontro consigo próprio na solidão, mesmo na imobilidade, mas que se transmuta em algo muito maior que isso, imenso.

A primeira ação que de fato acontece no tempo presente do poema surge a partir de uma negativa, no décimo verso: “Não o faço". Esse momento é como uma decisão. $\mathrm{O}$ "sim" seria continuar naquele espaço. Ao decidir voltar para a outra vida, a sua mesmo, o eu-lírico abre a porta. E esse abrir, que é uma ação que normalmente denotaria abertura, nesse caso, sugere fechamento para o espaço em que se estava antes. O próprio verso possui uma subitaneidade que é como uma decisão feita porque era necessário fazê-la, o que também transparece na forma, a partir de um trímetro anapéstico, que sugere uma urgência no 
movimento (e que retoma os primeiros versos, também repletos de anapestos) e condiz com o movimento súbito de abandonar a cadeira e abrir a porta para entrar na casa e deixar de fora a vida imaginária, cuja rima toante com "casa" evidencia a oposição.

De acordo com Tynianov (1975a), o ritmo do poema é decisivo para o movimento geral do poema, de modo que o metro dinamiza os versos mesmo quando não é correspondido de maneira igual, pois as antecipações não concluídas também dinamizam. Levando isso em consideração, pode-se perceber que, enquanto no geral o poema possui uma métrica bastante mista, os dois últimos versos são octossílabos e em dupla encerram uma mesma ideia: daquela vida "imaginária" que é deixada no jardim. As partes "e deixo devoluta" e "a vida / imaginária" possuiriam o mesmo número de sílabas métricas e de acentos, porém "a vida" não fica no mesmo verso de seu adjetivo qualificador. Ainda segundo Tynianov (1975b, p. 24), a evidenciação de uma palavra pode acontecer a partir da não-coincidência entre os limites da série e da unidade sintática, e, dessa forma, "indicar e aprofundar nuances particulares na combinação das partes da proposição". Dessa forma, ao isolar em um verso "imaginária no jardim", o poema destaca a primeira palavra, reforçando a qualidade irreal daquilo que foi deixado, além de unir isso ao espaço do jardim, isolado do resto, criando com esse verso um ambiente quase estrangeiro que representa essa vida de devaneios frente à "vida real".

Este é, em certo sentido, um poema melancólico - o que se evidencia no caráter muito nasalizado de alguns versos - porque no final se torna necessário voltar para aquela vida outra, que não é do imaginário e da interioridade - e que também não é a da experiência, que está ligada ao gesto de interrupção. Há algo que foi perdido e que não é dito em inteireza, mas se relaciona a esse encontro do eu consigo próprio. A lacuna constante do ser, abafada, mas 
palpável, está relacionada ao olhar melancólico que, de acordo com Francisco José Gomes Correia (2004, p. 52), tem como característica a predisposição:

à contemplação e a uma exacerbada consciência de si mesmo. A meditação corresponde ao impulso que lhe é característico de sondar o micro e o macrocosmos - que aparecem, por efeito de projeção, como enigmas da própria subjetividade.

Existe uma cisão, representada pela porta, entre essa vida "imaginária", que é como uma meditação no espaço do jardim, onde a melancolia sem tragédias se exerce, e a vida real, para a qual é preciso voltar-se. As palavras "deixa", "devoluta" e "vida" estão intrincadas entre si, em uma corrente gerada pelas aliterações em /d/ e /v/. Essas semelhanças criam uma sugestão de inevitabilidade, como se uma devesse acompanhar a outra e não houvesse outras possibilidades. É necessário deixar aquela outra vida, a vida necessariamente devoluta, palavra que se evidencia dentro do poema, devido ao seu /u/ duro, (e alongado pelo /1/), que não estava entre as sonoridades anteriores no poema e surpreende por sua crueza ao mostrar o vazio que habita o ambiente.

No momento em que o eu-lírico relaciona esse instante no jardim à vida que ocorre em outros espaços, realiza-se uma espacialização da própria subjetividade. Susan Sontag (1986), em um ensaio sobre a melancolia na obra de Walter Benjamin, afirma que o sujeito "saturnino", ou seja, o melancólico, culturalmente regido por Saturno, tem a tendência de espacializar o mundo, já que o tempo traz repressão e repetição. "No tempo, somos apenas o que somos: o que sempre fomos. No espaço, podemos ser outra pessoa" (SONTAG, 1986, p. 90). Por isso, enquanto o tempo traz a continuidade da vida, com toda sua repetição e estreiteza do presente que desemboca no futuro, a mudança de espaços pode garantir uma quebra nesse ciclo, pode ser um propulsor de possibilidades. Mesmo que, no poema, se tratem de lugares próximos, envoltos no cenário doméstico, a passagem de um para outro é representativa de um 
determinado estado de espírito. No andamento do poema, a última ação, de entrar em casa, indica possivelmente a volta para a vida regida pelo tempo, mas, ainda assim, a melancolia apresentada ali é viva, sem peso, aberta, ainda que frágil, porque existe essa outra vida disponível, de "dentro da cabeça". O espaço do jardim é também uma mudança de mentalidade, sugerindo a possibilidade que a melancolia encontra de, em novo espaço, se abrir para novas passagens dentro do eu.

Há uma necessidade de se perder na própria solitude, e é isso que garante o "sol" do poema. Seu caráter solar está nos momentos dessa outra vida de experiências, de deslocar a cadeira no jardim. O título sorri a essa vida imaginária, uma vida introspectiva, mas ensolarada pela própria observação. A vida no jardim é uma vida, e não seria assim se fosse apenas um momento. Apesar de ter ficado desabitada, continua ali como um abrigo. A vida dos acontecimentos tem suas contingências que obrigam a voltar à casa, mas o jardim espera. Trata-se de uma possibilidade de experiência.

Essa vida interior poderia ser vista - talvez pensando o sol em uma varanda florida; afinal, pelo caráter imaginário, o jardim não precisa ser de fato um jardim - como o próprio lugar de onde os outros poemas brotam, o espaço de germinação debaixo do sol e dentro da cabeça. Considerando o sol como "a fonte da luz, do calor, da vida" (CHEVALIER; GHEERBRANT, 2001, p. 836), cujo brilho torna tudo manisfesto, a vida interna, que se desloca como um girassol em seu encalço, talvez seja mais vida que a outra. E, se o sol também aparece, de forma simbólica, como o coração do céu, por estar em seu centro, e "como um símbolo de ressurreição e de imortalidade" (CHEVALIER; GHEERBRANT, 2001, p. 836), essa vida é capaz de ressurgir a cada criação. 


\section{A SOLIDÃO E AS PERGUNTAS}

Agora passamos ao segundo poema, "Banquete", em sua tematização dessa vida interior:

1. Sento-me sozinha à mesa

2. e obrigo-me a pensar no absurdo.

3. Não faço perguntas.

4. Elas sentam-se a meu lado

5. com um à-vontade cruel. (CHAVES, 2018, p. 17)

Esse poema constrói-se a partir de uma relação entre um eu reflexivo e suas perguntas, que, personificadas pelo verbo "sentar", tornam-se agentes. Isso se cria através da relação entre os dois primeiros versos e os dois últimos, que claramente se imbricam, dividindo o poema. "Sentar" é o verbo principal, e é o único que se repete. A relação do eu-lírico com suas perguntas se dá principalmente na associação entre os pronomes oblíquos "me", no primeiro verso, e "se", no quarto verso, representando a mudança de foco do eu para as perguntas, que passam a fazer companhia. Dessa forma, um verso está em paralelo com o outro, a partir da troca de sujeitos, dos pronomes oblíquos, e também daquilo que vem depois do verbo. Enquanto em um verso o que se segue é "sozinha", no outro é "a meu lado", sugerindo que de alguma forma as perguntas colocam-se em oposição à solidão. Elas agem como presenças, o que se relaciona com os versos do poema anterior: "é dentro da cabeça / e fora da minha vida / que me sinto menos só" - que, não por acaso, é o poema que lhe antecede na ordem do livro.

Além disso, ambos os verbos são heptassílabos, sugerindo também na forma a relação que estabelecem, enquanto os dois versos seguintes - o segundo e o quinto - são ambos octossílabos e também formam um paralelismo entre si. “E obrigo-me a pensar no absurdo" e "com um à-vontade cruel" estão em uma 
relação que aparece principalmente no modo como os termos "obrigo-me" e "à vontade" se antagonizam nesse contexto - oposição que é evidenciada pelo ritmo que constrói o verso e que, de acordo com Tynianov (1975a), age como seu princípio dinâmico. Dessa forma, entre os dois verbos, um denota uma espécie de imposição a si mesma, enquanto o outro sugere a naturalidade com que as perguntas se fazem, como se nem precisassem dela para isso, de tão emergentes.

A ação principal é dessa busca, que é consciente e proposital, por algo que está na ordem do pensamento, e só pode ser encontrado em um estado de solitude. "A necessidade de estar só - assim como a amargura da própria solidão - é característica do melancólico. Para que o trabalho seja realizado, precisamos estar sós" afirma Sontag (1986, p. 99), e o trabalho ao qual a autora se refere é o próprio trabalho de pensar, cultivado como uma forma de introspecção constante. Essa relação com o pensamento também é referenciada por Correia (2004) ao se referir ao comportamento melancólico a partir de seu caráter reflexivo, caracterizado por uma sondagem do micro e do macrocosmo a partir da subjetividade.

Por isso, é importante a sugestão desse momento "sozinha à mesa" expressão que, apesar da sibilância na relação entre "sentar" e "sozinha", carrega em si uma aspereza em sons de /z/, mostrando, talvez, que não se trata de um movimento fácil esse de refletir-se; é necessário um fechamento inicial, uma introspecção para chegar até as perguntas essenciais. As vogais fechadas, abundantes nesse primeiro momento, como em "sozinha", "mesa”, "obrigo-me” e "absurdo", iconizam esse movimento de fechamento em si, de introspecção. Obrigar-se a pensar no absurdo é entrar no estado de procura dentro de si.

Michel de Montaigne, em seu ensaio "Sobre a solidão", fala sobre a importância desses momentos sozinhos para que se possa reaver-se, por isso a necessidade de reservar um espaço próprio e praticar a solidão enquanto liberdade, considerando que, para o filósofo, "A maior coisa do mundo é saber 
pertencer a si mesmo" (MONTAIGNE, 2002, p. 361). O fechamento que o poema realiza é uma abertura nessa solidão, para tentar encontrar algo em si, mesmo as próprias perguntas frente ao absurdo. E pensar no absurdo já é praticamente um paradoxo, se considerarmos que pensar pressupõe o uso da razão para chegar a alguma conclusão, a partir da elaboração de um raciocínio, enquanto absurdo indica o que é isento de sentido, nexo ou propósito. O próprio ritmo desse verso, em relação ao primeiro, parece um pouco deslocado, devido aos acentos em lugares distintos, como se esse "obrigar-se" não fosse um movimento natural.

O pensamento dirige-se a algo que não pode ser completamente apreendido, que não se subscreve às leis do racional, ultrapassando o nosso entendimento, então não é possível haver respostas para os questionamentos. É natural do ser humano buscar por certezas e por fixidez e, nessa busca, desprezase, muitas vezes, aquilo que gera mais perguntas que respostas. Então não é fácil pensar no absurdo, o que torna necessário "obrigar-se" a esse movimento.

Essa ação de refletir - de perguntar-se muitos mais do que responder - é também a ação de fazer silêncio. Segundo Michele Federico Sciacca (1967), o silêncio sempre carrega sentidos que são muito mais amplos do que as palavras que buscam traduzi-lo. A linguagem é formada de palavras e de silêncios. É da quietude da interioridade que nascem as palavras e é a ela que as palavras retornam. O silêncio é uma forma de escuta e de mergulho e, exatamente por isso, não é fácil entregar-se a ele, porque, muitas vezes, ele revela algo que não se deseja revelar e gera as perguntas que estavam amortecidas:

O silêncio tem um peso psicológico que não encontramos em nenhuma palavra: é pesado por tudo que vivemos, por tudo que estamos vivendo e por tudo o que viveremos. Um instante de silêncio, todo o peso do tempo de nossa vida: está carregado de todas as recordações, de todas as presenças, de todas as ausências, de todas as esperanças e de todas as desilusões. Num instante de silêncio se recolhe uma vida inteira. [...] É uma recapitulação que obsessiona, oprime; uma espécie de palco no qual estão presentes simultaneamente todos os personagens da nossa existência. (SCIACCA, 1967, p. 37) 
Dessa forma, a ação de se sentar à mesa e obrigar-se a pensar é algo que se acresce de toda essa vida interior que então se passa a encarar. No momento de silêncio, há uma emergência da vida inteira e, com isso, as perguntas sem fim, inevitáveis. O momento de questionar o absurdo é o momento de voltar-se para si, e também é o movimento de interrupção de que fala Bondía (2002), aquele necessário para que haja a experiência. Sob o véu de uma aparente imobilidade, essa ação é parte de uma procura mais ampla, que não é uma procura com um objetivo final, mas que enfoca esse presente na busca por uma compreensão impossível, que, assim como as pessoas na procissão, no poema "Santos populares”, “[...] parecem / tão certas de não irem / a lado nenhum” (CHAVES, 2018, p. 10).

O verso central - que está entre os dois pólos do poema, embora pertença à segunda estrofe - é "não faço perguntas", que, apesar de operar por meio de uma negação, liga os dois primeiros aos dois últimos, já que as perguntas são o que surgem dessa reflexão inicial. O eu-lírico, porém, não se considera como o propositor das questões. Elas surgem à revelia. São, no entanto, sintomas desse pensamento no absurdo, como indica a própria rima toante que as duas palavras mantêm. É nesse ponto que o "elas" do verso seguinte indica uma quebra. Quem realiza as ações já não é o eu-lírico, mas as perguntas que se personalizam e tomam a dianteira fazendo-se presença.

Conforme o poema vai chegando ao final e as perguntas assumem o controle, as vogais se tornam mais abertas, em palavras como "elas", "faço", "lado", "à vontade", "cruel”, visto que, ao mesmo tempo que há esse fechamento necessário à reflexão, representado na primeira estrofe, há uma abertura para que as perguntas surjam. Pensar no absurdo já é pressupor que elas aparecerão. E, de fato - como a própria sonoridade indica - elas abrem espaço para si junto à 
mesa, e mais do que isso, abrem o próprio pensamento às distintas possibilidades: imensidão.

O "à vontade" substantivado indica esse movimento das perguntas, que chegam com liberdade, sem barreiras possíveis. De acordo com Tynianov (1975b, p. 48), no verso "[...] as palavras se encontram em relações mais fortes e mais estreitas do que no discurso corrente". Dessa forma, pode-se notar que o "àvontade", que carrega uma potência significativa maior devido a sua substantivação, está ligado intimamente ao termo que o adjetiva, "cruel". O que se salienta nessa adjetivação é que não são as perguntas que são cruéis, nem o próprio absurdo em que se pensou: a crueldade está na forma fácil, sem filtro, com que as perguntas agora chegam, obrigando a rever tudo com outros olhos, sabendo que as respostas não serão possíveis. É cruel a eterna lacuna que gera a melancolia quando se encara o absurdo de si e do mundo. Se "cruel" relacionase com o gosto por causar dor, esse modo como as perguntas chegam não retrocede frente à dor das incertezas. Trata-se de uma abertura, mas nem toda abertura é fácil: às vezes, é estar em carne viva.

Por fim, nos voltemos ao título. Banquete. Uma mesa, como há no poema, mas não a mesa de um sujeito sozinho. Banquete pressupõe outras presenças, fartura, festim, e, muitas vezes, até o sagrado. “De modo geral, é um símbolo de participação numa sociedade, num projeto, numa festa" (CHEVALIER; GHEERBRANT, 2001, p. 120). Essa dimensão surge na profusão de perguntas que, como convivas dessa anfitriã até então solitária, chegam em um número indefinido, invadem, ocupam os espaços, transformando tudo em uma grande conversa que é a conversa do indivíduo consigo mesmo em sua introspecção. Um banquete de dúvidas: convivas rudes, mas essenciais. Com as reflexões, na solidão e no silêncio, comunga-se do absurdo existencial. 
O último poema a ser analisado chama-se "Primeiro: continuar; Segundo, começar", e apresenta outra forma de procura interior.

1. Se não escrevo, leio.

2. Não descanso até encontrar

3. o poema que me alivie.

4. Encontrarei palavras

5. que me emprestem sentido.

6. É um modo de sobrevivência que pratico,

7. procurar casas dentro de casa.

8. Transporto uma candeia discreta e vejo

9. nos poetas-irmãos e nos poetas-amantes,

10. sossego para as emoções que me fazem cerco.

11.Fecharei os olhos

12.quando me sentir iluminada por dentro. (CHAVES, 2018, p. 30)

O título deste poema refere-se a uma conferência ministrada em 2016 pela teórica portuguesa Maria Filomena Molder, e que faz parte de um ciclo de conferências intitulado "Não te esqueças de viver!" (título de outro poema de Marta Chaves). Em sua segunda palestra intitulada, como o poema, "Primeiro: continuar. Segundo: começar", Molder inicia comentando um texto de Fernando Gil sobre Sá de Miranda, no qual o primeiro, em um dado momento, assume-se como um "eu" leitor. A estudiosa reflete sobre esse ato de nos deixarmos refletir pelo texto do outro e nos lermos a partir da estranheza em "um ato de conhecimento que se transmuta em autoconhecimento" (MOLDER, 2016, n.p.). Não é sem motivos que essa conferência dá nome ao poema, visto que ele versa justamente sobre o movimento que Molder descreve: encontrar-se naquilo que se lê.

A temática central da leitura já se expressa no primeiro verso. O poema inicia com uma pausa: "se não escrevo, leio". O próprio ritmo obriga a parar, de 
forma que o verbo "ler" se torna evidenciado, além do fato de que é nele que o verso termina - e que a própria frase termina - tornando o ato mais contundente. $\mathrm{O}$ "não descanso", no verso seguinte, retira qualquer possibilidade de tratar-se de uma leitura desinteressada. Há uma busca e, nela, uma obstinação. Os livros não são lidos passivamente: procura-se neles, com afinco, algo que alivie, que dê sentido. O próprio poema representa essa procura em seu ritmo, que não é de uma imobilidade passiva, mas que evidencia a própria atividade em sua abundância de verbos. De fato, é um poema repleto de verbos: há verbos em quase todos os versos, às vezes, mais de um. A profusão de ações sugere um eu-lírico ativo na busca pelas palavras que lhe digam. $\mathrm{O}$ poema não sossega. $\mathrm{O}$ sossego possível está em uma dimensão futura, porque, no presente, estamos todos procurando.

O poema buscado é um que dê alívio, como um lenitivo existencial. A busca por compreender a si mesmo se realiza no contato com a literatura. $\mathrm{O}$ poema é o espaço procurado para aliviar essa vontade que se traduz em angústia, e ele faz isso, não ao nublar aquilo que não se sabe, mas ao emprestar sentidos. Sciacca (1967, p. 31), em suas reflexões sobre o silêncio, afirma que: “também quem ouve, lê, vê, reflete: cria a sua zona de vasto silêncio, e deixa que ali caiam as palavras dos outros, que o seu silêncio transforma em verbo pessoal que o desvela". Ou seja, essas palavras alheias, presentes nos livros, entram no silêncio reflexivo daquele que as lê e se tornam um pouco suas próprias palavras. Ler é produzir. Nesse ponto, a relação é oposta àquela em que primeiro se pensa, quando consideramos o contato com as palavras em um livro. Nesse caso, não é o indivíduo que empresta sentido a elas, em uma atividade de interpretação, mas é a própria palavra que vai ajudá-lo a interpretar-se. Quando lemos um poema, lemos a nós mesmos.

A busca por palavras nos livros é uma busca de palavras para si, por isso ler é apresentado no mesmo nível, com o mesmo estatuto de escrever: ambos são 
formas de autoconhecimento, e, ao mesmo tempo, de entrar em um contato mais profundo com o mundo, efetivamente, ter uma experiência. No entanto, o verbo "emprestar" sugere algo temporário, ou seja, as palavras são capazes de fornecer sentidos em um determinado momento, mas esses sentidos, naturalmente, se esvanecem no andamento da vida. Depois, é necessário continuar procurando por outros. O sentido é emprestado, o que não o torna menos real, mas torna a busca infinita.

Essa procura infinda no terreno dos livros se aproxima à sensação de falta sem um objeto definido, que é característica da melancolia. Nunca se encontra plenamente aquilo que se deseja; o que há são sentidos emprestados, provisórios, que logo se dissolvem. Porém, há uma aceitação dessa procura, um gosto por esse tipo de mergulho, que também está presente na vida imaginária ao sol e nos pensamentos sobre o absurdo, e que traz consigo a sensibilidade de uma melancolia sem tragédia, como colocado por Lourenço (1999), sintonizada com a própria falta. Há, manifesto nessa escrita, um olhar, mais leve, com gravidade, mas sem o peso do trágico - um olhar característico de uma melancolia que seria, como nas palavras de Italo Calvino (1990, p. 32), “a tristeza que se tornou leve”.

Essa busca inesgotável no terreno dos livros, trazida na primeira estrofe, é melhor explorada na segunda. O tamanho dos versos aumenta visivelmente em relação aos anteriores, o que gera um efeito de expansão na página, e, principalmente, no ritmo da leitura, que se alonga como uma explicação daquela busca que a primeira estrofe explicita. É como se os versos trouxessem um "por quê" e um "como" para dilatar o que já foi expressado. O verso 6 apresenta-se como uma justificativa, porém a palavra "sobrevivência" já quebra o andamento rítmico, sendo a maior palavra do poema em número de sílabas, e, ainda, contendo um encontro consonantal que esbarra no de "pratico", realçando sonoramente o verso e revelando sua importância para esclarecer o conjunto geral. É um modo de sobrevivência. Além disso, ele está relacionado pela métrica 
ao verso "Quando me sentir iluminada por dentro" - ambos são os únicos dodecassílabos no poema - e também pelas ideias, sendo um resultado do outro. Essa sobrevivência é precisamente a busca pela iluminação interna, que nunca acontece de todo - se acontecesse, não haveria nada depois - mas que, pela própria busca, já vale enquanto forma de sobreviver.

Os poemas, e, por extensão, o sentido que fornecem ao eu-lírico, são as “casas dentro de casa". A metáfora presente no verso 7 mostra como, dentro do espaço físico da casa, os livros - e, por extensão, os poemas; e, por extensão, o sentido que neles se encontram - também são casas. Eles abrigam e protegem, ocupam a função de um lar, mesmo que um lar emprestado. E, se a casa já é o espaço íntimo, esses poemas se tornam o íntimo do íntimo, algo que é maior que o eu-lírico, mas que o encompassa como um útero. Segundo Bachelard (1978), a casa é o espaço que ocupamos no mundo, algo próprio, um universo particular. Além disso, tudo que, de alguma forma, habitamos trará consigo a noção simbólica da casa, sua essência. Desse modo, os livros se apresentam como um lugar onde se possa habitar, que é o contrário de estar disperso no mundo.

Eles são, de acordo com Sontag (1986, p. 97), “uma miniaturização do mundo, que o leitor habita", ou seja, pequenos mundos onde se torna mais fácil pertencer, encontrar-se, deparar-se consigo e com o outro das páginas. Desse modo, nos sentidos que provêm, os poemas são mundos, dentro do mundo dos livros, dentro do mundo da casa. Mesmo que de forma momentânea, abrigam o eu que andava de forma errática, sem respostas, e lhe dão uma morada. Por isso, são procurados, e essa procura acontece dentro do próprio espaço da casa. Tudo na segunda estrofe, especialmente seu final, sugere uma imagem: o sujeito lírico carregando uma candeia, enquanto passa pelos livros, a procurar, nas lombadas, pelo poeta (irmão ou amante) em cujos poemas poderia se encontrar. A luz da candeia também é uma iluminação em algo que até então estava escuro. O sujeito lírico ilumina externamente os livros que o iluminam por dentro. Há um jogo 
representado pelos timbres, entre esse interior melancólico, o "dentro", que procura ler e escrever (representados por vogais fechadas, como em "leio", "escrevo" e "cerco"), e a iluminação que vem de fora, a partir desses poetas (representada pelas vogais abertas como "encontrar", "palavras", "casas", “iluminada", e o próprio "poetas"). Porém essa iluminação, ao mesmo tempo que vem de fora, não deixa de ser de dentro, já que ela parte de suas emoções para aquilo que é externo. As vogais abertas e fechadas coexistem ao longo do poema, como em "candeia discreta", lado a lado, ora um tipo sendo iluminado, ora outro, como as luzes da candeia sobre os livros.

O eu-lírico foca sua busca nos "poetas-irmãos" e "poetas-amigos", o que mostra, em primeiro lugar, que as relações estabelecidas diferem, dependendo do poeta, e, em segundo lugar, que a relação poeta-leitor foi tornada íntima. Talvez não haja como emprestar sentidos sem algum grau de intimidade. Os versos 9 e 10, que falam sobre os poetas e o sossego que causam nas emoções, possuem ambos treze sílabas poéticas e são os maiores versos do poema, sugerindo, talvez, esse sentimento expandido, essa procura nos poetas, esse conforto que provêm, de forma a estirar o verso como um afago prolongado, um momento de afeto e compreensão frente ao absurdo existencial.

É preciso procurar pelo sossego, porque as emoções "fazem cerco". Elas colocam o eu em estado de sítio, e ler torna-se sobreviver ao realizar a ação de sossegá-las, não pela repressão, mas pelo entendimento: o autoconhecimento, como o proclamado na conferência que dá título ao poema, em que, a partir da leitura de um outro, investiga-se a "vertigem das razões de ser" (MOLDER, 2016, n.p.). Essa busca dá sentido ao próprio ser, mas ao mesmo tempo não é sempre tranquila; pode ser dolorosa como o pensamento no absurdo, do poema anterior. A sonoridade do poema, de metros com pouca regularidade e de muitos encontros consonantais, demonstra isso: não se trata de uma busca objetiva, em linha reta, que deslize fácil. É uma busca inacabável, que se faz em meio aos 
conflitos, afinal, "o eu é um texto - precisa ser decifrado. [...] O eu é um projeto, algo a ser construído" (SONTAG, 1986, p. 91); é um trabalho consciente e uma relação sempre ambígua.

A terceira estrofe fala sobre a iluminação interna, porém como algo que não foi encontrado. Por isso, apresenta-se em um tempo futuro. O resultado dessa iluminação será o fechar de olhos, imagem que pode ser pensada de duas maneiras. "Fecharei os olhos" pode remeter à tranquilidade de enfim poder descansar da procura, o que retoma o sentido dos versos "não descanso até encontrar" e "sossego para as emoções que me fazem cerco". Pode-se abrir mão da busca por já estar iluminada, mesmo que temporariamente. Dessa forma, seria um fechar de olhos que remete a um tempo imediato, causado pelo alívio, logo após ler o poema que lhe empreste algum sentido.

Porém, também se pode ler o sentido de "fecharei os olhos" como algo permanente. Nesse caso, seria o último fechar de olhos, supremo descanso e supremo sossego, pois, como os sentidos são temporários, só na morte é possível parar completamente com a busca. Quando há a iluminação completa, nada mais resta, pois não há mais sentido em buscar-se nos livros, contemplar-se por dentro sob o sol ou pensar no absurdo. Essa calma das certezas aproxima-se muito àquela da morte, como diz a poeta em outro poema do livro: “Esta calma / fazme pensar que estou certa / ou morta" (CHAVES, 2018, p. 9).

\section{CONSIDERAÇÕES FINAIS}

Se pensarmos nesses poemas, a partir das imagens que expressam, como três distintos momentos, três instantâneos de interiores, podemos dispô-los da maneira a seguir.

Primeiro momento: deslocar a cadeira no encalço sol, dando vazão ao mundo interior que, na aparente imobilidade, se destaca e assume o lugar da 
vida, mesmo que passageiramente. Segundo momento: sentar sozinho à mesa, refletindo sobre o que não possui respostas ou razão, e se deixar invadir por perguntas que surgem à revelia, a partir da abertura deixada. Terceiro momento: com uma candeia acesa, procurar nos livros de diversos poetas por poemas que ajudem a ler a si próprio e, a partir desse intercâmbio de sentidos, aplacar as próprias angústias.

O que há em comum nesses poemas são os temas que mais se destacam nessa varanda de inverno: a solidão (muitas vezes intencional), a introspecção, a busca interna, a procura por sentidos unida à aceitação de que haverá sempre perguntas e incertezas. São poemas que não se constrangem de mostrar a própria subjetividade e as impressões de um encontro poético com o mundo. Sobre o modo como escreve seus poemas, Marta Chaves (2013, n.p.) comenta em entrevista: “Escrevo para me tornar reconhecível para mim própria [...] para não perder a sensibilidade. Não me quero tornar espectadora". Essa ação de reconhecimento de si, a partir de uma escuta ativa, em um exercício de sensibilidade quanto ao que a rodeia, é algo que se mostra de forma evidente no andamento dos poemas.

"É dentro da cabeça / e fora da minha vida / que me sinto menos só" dizem os versos de "Solar", e poderíamos talvez lê-los como uma poética geral, que se espalha pelos outros poemas do livro, ora de forma aparente, ora sutilmente. Eles são poemas dessa outra vida, da vida da cabeça, da interioridade, da imaginação nos jardins (e varandas). São poemas de uma melancolia suave, que disfarça uma busca interna e lancinante. Eles não gritam, ao contrário, se viram para dentro e “assobi[am] sem que se ouça" (CHAVES, 2018, p. 29).

Sob o silêncio do eu que se retrai - e do poema que se contrai e obriga a leitura depreender sentidos - muito está sendo dito. A solidão existe e não há como escapar, às vezes, ela é buscada, às vezes, se dá pela falta (como nos poemas que se dirigem para um "tu" ausente). Mas nesse estado de "dentro da cabeça", 
há uma miríade de perguntas a serem contempladas e um mundo a ser visto a partir de si, como se cada poema fosse uma travessia em direção a determinados sentimentos ou reflexões, percorrendo-os conforme o eu dos poemas percorre a si, em uma procura que é sempre solitária.

\section{REFERÊNCIAS}

BACHELARD, Gaston. A poética do espaço. Tradução por Antônio da Costa Leal e Lídia do Valle Santos Leal. São Paulo: Abril Cultural, 1978.

BONDÍA, Jorge Larrosa. Notas sobre a experiência e o saber da experiência. Revista Brasileira de Educação, n. 19, 2002, p. 20-28

CALVINO, Italo. Seis propostas para o próximo milênio. Tradução por Ivo Barroso. São Paulo: Companhia das Letras, 1990.

CHAVES, Marta. Poetas como nós. Repórter à solta. Entrevista concedida a Paulo Moura. 29 Mai, 2013. Disponível em: <http://blogues.publico.pt/reporterasolta/poetas-comonos/>. Acesso em: 28/07/2019

CHAVES, Marta. Varanda de inverno. Lisboa: Assírio \& Alvim, 2018.

CHEVALIER, Jean; GHEERBRANT, Alain. Dicionário de símbolos. Tradução por Vera da Costa e Silva. Rio de Janeiro: José Olympio, 2001.

CHKLOVSKI, Victor. A arte como procedimento. In: EIKHENBAUM et al. Teoria da literatura: formalistas russos. Tradução por Ana Mariza Ribeiro Filipouski. Porto Alegre: Globo, 1971. p. 39-56

CORREIA, Francisco José Gomes. Subsídios para uma poética da melancolia: depoimento. Revista da ANPOLL, São Paulo, n. 16, p. 43-55, 2004

LOURENÇO, Eduardo. Mitologia da Saudade seguido de Portugal como Destino. São Paulo: Companhia das Letras, 1999

MOLDER, Maria Filomena. Primeiro: continuar. Segundo: começar. Conferência Cultergest, Lisboa, 15 de fevereiro de 2016. Disponível em: $<$ https://vimeo.com/155541511>. Acesso em 1\%/08/2019

MONTAIGNE, Michel. Os ensaios. Tradução por Rosemary Costhek Abílio. 2 ed. São Paulo: Martins Fontes, 2002. Livro I.

SCIACCA, Michele Federico. Silêncio e palavra. Tradução por Flávio Loureiro Chaves e Maria Teresa Pasquini. Porto Alegre: Nação, 1968.

SONTAG, Susan. Sob o signo de Saturno. In: SONTAG, Susan. Sob o signo de Saturno. Tradução por Ana Maria Capovilla e Albino Poli Jr. Porto Alegre: L\&PM, 1986.

TYNIANOV, Iuri. O problema da linguagem poética I: o ritmo como elemento 
constitutivo do verso. Tradução de Maria José Azevedo Pereira e Caterina Barone. Rio de Janeiro: Tempo Brasileiro, 1975a.

TYNIANOV, Iuri. O problema da linguagem poética II: o sentido da palavra poética. Tradução de Maria José Azevedo Pereira e Caterina Barone. Rio de Janeiro: Tempo Brasileiro, 1975b.

Nota do editor:

Artigo submetido para avaliação em: 26 de março de 2021.

Aprovado em sistema duplo cego em: 02 de setembro de 2021. 